\title{
Geographical Distribution of Ljungan Virus in Small Mammals in Europe
}

Cristina Fevola,${ }^{1,2}$ Chiara Rossi, ${ }^{1}$ Fausta Rosso, ${ }^{1}$ Matteo Girardi, ${ }^{1}$ Roberto Rosà,${ }^{1,3}$ Mattia Manica,${ }^{1}$ Luca Delucchi, ${ }^{1}$ Duccio Rocchini, ${ }^{1,3,4}$ Carol X. Garzon-Lopez, ${ }^{1,5}$ Daniele Arnoldi, ${ }^{1}$ Alessandro Bianchi, ${ }^{6}$ Elena Buzan, ${ }^{7}$ Nathalie Charbonnel, ${ }^{8}$ Margherita Collini, ${ }^{1,9}$ L'udovít

Ďureje, ${ }^{10}$ Frauke Ecke, ${ }^{11}$ Nicola Ferrari, ${ }^{9}$ Stefan Fischer, ${ }^{12}$ Emma L. Gillingham, ${ }^{1,13,14}$ Birger Hörnfeldt, ${ }^{11}$ Mária Kazimírová, ${ }^{15}$ Adam Konečný, ${ }^{1,16}$ Miriam Maas, ${ }^{17}$ Magnus Magnusson, ${ }^{11}$ Andrea Miller, ${ }^{18,19}$ Jukka Niemimaa, ${ }^{20}$ Åke Nordström, ${ }^{11}$ Anna Obiegala, ${ }^{21,22}$ Gert Olsson, ${ }^{11}$ Paolo Pedrini, ${ }^{23}$ Jaroslav Piálek, ${ }^{10}$ Chantal B. Reusken, ${ }^{17,24}$ Franco Rizzolli, ${ }^{1}$ Claudia Romeo, ${ }^{9}$ Cornelia Silaghi, ${ }^{21,25}$ Tarja Sironen, ${ }^{2}$ Michal Stanko, ${ }^{15,26}$ Valentina Tagliapietra, ${ }^{1}$ Rainer G. Ulrich, ${ }^{12}$ Olli Vapalahti, ${ }^{27,28}$ Liina Voutilainen, ${ }^{20}$ Lucas Wauters, ${ }^{29}$ Annapaola Rizzoli, ${ }^{1}$ Antti Vaheri, ${ }^{2}$ Anne J. Jääskeläinen, ${ }^{2,27}$ Heikki Henttonen, ${ }^{20}$ and Heidi C. Hauffe ${ }^{1}$

1Department of Biodiversity and Molecular Ecology, Research and Innovation Centre, Fondazione Edmund Mach, San Michele all'Adige (TN), Italy.

2Department of Virology, Faculty of Medicine, University of Helsinki, Helsinki, Finland.

${ }^{3}$ Centre for Agriculture, Food and the Environment, University of Trento, S. Michele all'Adige (TN), Italy.

${ }^{4}$ Centre for Integrative Biology, University of Trento, Povo (TN), Italy

5present address: Ecology and Vegetation Physiology Group (EcoFiv), Universidad de los Andes, Bogotá, Colombia

6Istituto Zooprofilattico Sperimentale della Lombardia e Dell'Emilia Romagna "Bruno Ubertini" Brescia, Italy.

${ }^{7}$ Department of Biodiversity, University of Primorska, Koper, Slovenia.

${ }^{8}$ CBGP, INRA, CIRAD, IRD, Montpellier SupAgro, Université de Montpellier, Montferrier sur Lez Cedex, France.

${ }^{9}$ Department of Veterinary Medicine, Università degli Studi di Milano, Milan, Italy.

${ }^{10}$ Institute of Vertebrate Biology, Academy of Sciences of the Czech Republic, Studenec, Czech Republic. 
${ }^{11}$ Department of Wildlife, Fish, and Environmental Studies, Swedish University of Agricultural Sciences, Umeå, Sweden.

${ }^{12}$ Friedrich-Loeffler-Institut, Federal Research Institute for Animal Health, Institute of Novel and Emerging Infectious Diseases, Greifswald-Insel Riems, Germany.

${ }^{13}$ School of Biosciences, Cardiff University, Cardiff, UK.

${ }^{14}$ present address: Department of Medical Entomology and Zoonoses Ecology, Public Health England, London, UK.

${ }^{15}$ Slovak Academy of Sciences (SAS), Institute of Zoology, Bratislava, Slovakia.

${ }^{16}$ present address: Department of Botany and Zoology, Masaryk University, Brno, Czech Republic

${ }^{17}$ Netherlands Centre for Infectious Disease Control, National Institute for Public Health and the Environment (RIVM), the Netherlands.

18Department of Biomedical Sciences and Veterinary Public Health, Section for Parasitology, Swedish University of Agricultural Sciences, Box 7036, SE-750 07 Uppsala, Sweden.

${ }^{19}$ Department for Terrestrial Ecology, Norwegian Institute for Nature Research, Trondheim, Norway.

${ }^{20}$ Natural Resources Institute Finland (LUKE), FI-00790 Helsinki, Finland.

${ }^{21}$ Comparative Tropical Medicine and Parasitology, Ludwig-Maximilians-Universität, Munich, Germany.

${ }^{22}$ present address: Institute of Animal Hygiene and Veterinary Public Health, University of Leipzig, Leipzig, Germany.

${ }^{23}$ MUSE - Museo delle Scienze di Trento, Italy.

${ }^{24}$ present address: Department of Viroscience, Erasmus University Medical Centre, Rotterdam, The Netherlands.

${ }^{25}$ present address: Institute of Infectology, Friedrich-Loeffler-Institut, Federal Research Institute for Animal Health, Greifswald-Insel Riems, Germany.

${ }^{26}$ Slovak Academy of Sciences (SAS), Institute of Parasitology, Košice, Slovakia.

27Department of Virology and Immunology, University of Helsinki and Helsinki University Hospital, Helsinki, Finland.

28Department of Veterinary Biosciences, University of Helsinki, Helsinki, Finland

${ }^{29}$ Department of Theoretical and Applied Sciences, Università degli Studi dell'Insubria, Varese, Italy.

Address correspondence to:

Heidi C. Hauffe

Department of Biodiversity and Molecular Ecology

Research and Innovation Centre

Fondazione E. Mach

Via E Mach 1

38010 S. Michele all'Adige (TN)

Italy

E-mail: heidi.hauffe@fmach.it 


\section{Abstract}

Ljungan virus (LV), which belongs to the Parechovirus genus in the Picornaviridae family, was first isolated from bank voles (Myodes glareolus) in Sweden in 1998 and proposed as a zoonotic agent. To improve knowledge of the host association and geographical distribution of $\mathrm{LV}$, tissues from 1685 animals belonging to multiple rodent and insectivore species from 12 European countries were screened for LV-RNA using reverse transcriptase (RT-)PCR. In addition, we investigated how the prevalence of LV-RNA in bank voles is associated with various intrinsic and extrinsic factors. We show that $\mathrm{LV}$ is widespread geographically, having been detected in at least one host species in nine European countries. Twelve out of 21 species screened were LV-RNA PCR-positive, including for the first time the red vole (Myodes rutilus), and the root or tundra vole (Alexandromys formerly Microtus oeconomus), as well as in insectivores, including the bicolored white-toothed shrew (Crocidura leucodon) and the Valais shrew (Sorex antinorii). Results indicated that bank voles are the main rodent host for this virus (overall RT-PCR-prevalence: 15.2\%). Linear modeling of intrinsic and extrinsic factors that could impact LV prevalence showed a concave-down relationship between body mass and LV occurrence, so that subadults had the highest LV positivity, but LV in older animals was less prevalent. Also, LV prevalence was higher in autumn and lower in spring, and the amount of precipitation recorded during the six months preceding the trapping date was negatively correlated with the presence of the virus. Phylogenetic analysis on the 185 base pair species-specific sequence of the $5^{\prime}$ untranslated region identified high genetic diversity (46.5\%) between 80 haplotypes, although no geographical or host-specific patterns of diversity were detected.

Keywords: rodent-borne, bank vole, reservoir host, zoonosis, Picornaviridae, RT-PCR, cartogram, GLM. 


\section{Introduction}

Since its discovery in bank voles (Myodes glareolus) from Sweden in 1998, Ljungan virus (LV; also referred to as Parechovirus B, family Picornaviridae), has been studied for its zoonotic potential (Niklasson et al. 1998; 1999). Early studies showed that LV-infected rodents and inoculated laboratory animals displayed human disease-like symptoms, and several publications have implicated LV in human disease, including gestational disease and those related to the central nervous system (Niklasson et al. 2007; 2009a; 2009b; Samsioe et al. 2009). Although specific disease symptoms have been associated with LV in humans (Fevola et al. 2016), interest was rekindled in the zoonotic potential of this virus after reports of high seroprevalences of anti-LV antibodies in Finnish residents, ranging from 33.8 to $47.8 \%$ (Jääskeläinen et al. 2016; Fevola et al. 2017b). Although previous authors hypothesized as early as 2003 that LV may be widespread (Johansson et al. 2003), very little is still known about its host range and geographical distribution, and previous research on potential hosts of LV has mainly focused on prevalence in a single country and/or potential host species/population.

To date, LV-RNA has been detected in wild rodents in Denmark (bank vole: Niklasson et al. 2003), Finland (bank vole: Jääskeläinen et al. 2013; field vole Microtus agrestis: Forbes et al. 2014; Fevola et al. 2017a), Italy (bank vole, yellow-necked mouse Apodemus flavicollis: Hauffe et al. 2010; red squirrel Sciurus vulgaris: Romeo et al. 2014), the UK (bank vole, field vole: Salisbury et al. 2014) and Sweden (bank vole, field vole, grey-sided vole Craseomys formerly Myodes rufocanus, Norway lemming Lemmus lemmus, wood lemming Myopus schisticolor: Niklasson et al. 1999; Niklasson et al. 2006; Fevola et al. 2017a), as well as in voles in the USA (montane vole Microtus montanus: Johansson et al. 2003; southern red-backed vole Myodes gapperi: Tolf et al. 2009). Reverse transcriptase (RT-)PCR-prevalences have ranged from 8 to $50 \%$ per population, with the highest prevalences found in bank voles in Italy (Hauffe et al. 
2010) and Sweden (Fevola et al. 2017a). As a result, this species is purported to be the main host of LV (Warvsten et al. 2017).

In this study, we used molecular screening of small mammals to investigate the presence of LV in 12 European countries and in bank voles and other potential hosts. In addition, we investigated how the prevalence of LV in bank voles is associated with various intrinsic (e.g. sex and age) and extrinsic factors (e.g. weather and other environmental parameters)

\section{Materials and Methods}

\section{Sample collection}

As the aim of the study was to gain basic knowledge of the host and geographical distribution of LV, convenience sampling was considered appropriate; that is, liver samples from 21 small mammal species that had already been collected during various work packages of the EU FP7 project EDENext (Emerging Diseases in a Changing European Environment; http://www.edenext.eu/; Table 1), as well as other ongoing studies of the authors were used. Confirming previous experience in collaborating laboratories, liver had been previously identified in HCH's laboratories as the most reliable organ for extracting LV-RNA in LVpositive rodents. For comparison and overall analyses, results presented here also include data from bank voles and yellow-necked mice from Italy previously published by Hauffe et al. (2010); red squirrels and grey squirrels from Italy published in Romeo et al. (2014), and 452 bank voles from Finland and Sweden published in Fevola et al. (2017a).

In the three Baltic States (Estonia, Latvia, Lithuania), as well as Croatia, France, Germany, Italy, Slovakia, Slovenia, and The Netherlands, animals were live trapped and euthanized the same day, and liver samples were dissected out and stored at $-20^{\circ} \mathrm{C}$ or lower. In Finland and Sweden animals were snap trapped using Finnish traps (Etutuote Ky, Vaasa, Finland), or FOX metal traps (DeuFa Fallen Produktions- und Vertriebs GmbH, D-94127 Neuburg, Germany), 
frozen at $-20^{\circ} \mathrm{C}$ and thawed and dissected at a later date. Liver samples from all countries were shipped to the Fondazione E. Mach, Italy on dry ice for RT-PCR analyses.

The 'age class' (functional groups related to maturation and breeding) of bank voles was estimated using body mass as a proxy (Escutenaire et al. 2002; Tersago et al. 2011), e.g. individuals were classified as 'juvenile' ( $<14 \mathrm{~g})$, 'subadult' (14-17.9g) and 'adult' $(\geq 18 \mathrm{~g})$, in combination with other indicators (Prevot-Julliard et al 1999). Individuals with descended or undescended testes and penile shaft were classified as males, while those with mammary glands (with or without visible nipples) and a vagina (open or closed) were classified as females (Jackson 1912).

Field work and small animal trapping were carried out with permission from the ethical committees in the respective countries according to their national laws (Czech Republic: authorized in the protocol PP 27/2007 (institutional and state committees of the Czech Academy of Sciences in 2007); France: authorized under French and European regulations on care and protection of laboratory animals: French Law 2001-486 issued on June 6, 2001 and Directive 2010/63/EU issued on September 22, 2010; all animal procedures (trapping, euthanasia) were pre-approved by the Direction des Services Vétérinaires of the Herault Department under Agreement B 34-169-1; Finland: snap trapping does not require ethical permits under the Finnish Act on Animal Experimentation 62/2006 and by the decision of Finnish Animal Experiment Board 16 May 2007; Germany: Small mammals were trapped using Sherman@live animal traps according to relevant legislation (H. B. Sherman Traps,Inc., Tallahassee, Fla. U.S.A.) (official permit Site R1:Regierung der Oberpfalz 55.1-8646.4-140, Site T:Regierung von Schwaben 55.1-8646-2/30, Site S: AZ 36.11-36.45.12/4/12-001). Additional sample collection was authorized according to relevant legislation and by permission of the federal authorities (permits Regierungspräsidium Stuttgart 35-9185.82/0261, Landesamt für Natur, Umwelt und Verbraucherschutz Nordrhein-Westfalen 8.87-51.05.20.09.210, Landesamt für Landwirtschaft, Lebensmittelsicherheit und Fischerei Mecklenburg- 
Vorpommern 7221.3-030/09, Thüringer Landesamt für Lebensmittelsicherheit und Verbraucherschutz 22-2684-04-15-107/09; Italy: authorized by the 'Comitato Faunistico Provinciale della Provincia di Trento', protocol n 595, issued on 04 May 2011; The Netherlands: authorized in compliance with Dutch laws on animal handling and welfare: RIVM/DEC permits 200700119, 200800053, 200800113 and 20100139; Slovakia: authorized according to current laws of the Slovak Republic, approved by the Ministry of Environment of the Slovak Republic, licence numbers 297/108/06-3.1, 6743/2008-2.1 and ZPO-594/2012SAB; Slovenia: authorized by the Ministry of Culture of the Republic of Croatia (No. 532-0801-01/1-11-03) and the Veterinary Administration of the Republic of Slovenia (No. 3440136/2012/9; Sweden: authorized under the Animal Ethics Committees of Umeå: A 44-08, A 6111, and A 121-11, the Swedish Board of Agriculture: A 135-12 and Dnr A78-08, and the Swedish Environmental Protection Agency: Dnr 412-2635-05, Dnr 412-4009-10, Nv 0293911).

\section{Molecular analysis}

RNA extraction was performed using the RNeasy Lipid Tissue MiniKit (Qiagen, Hilden, Germany) according to the manufacturer's instructions. Using an LV-specific one-step RT-PCR method targeting a 185 base pair (bp) sequence of the 5' untranslated region (UTR) (DonosoMantke et al. 2007), liver samples were screened for LV-RNA and confirmed by sequencing as previously described in Fevola et al. (2017a). RT-PCR products were purified either directly or from agarose gel using the PCR Purification Combo Kit (Invitrogen, Carlsbad, CA, USA) in combination with the PureLinkt Quick Gel Extraction kit (Invitrogen). Purified DNA was sequenced in both directions using a BigDye Terminator cycle sequencing kit (Perkin Elmer, Applied Biosystems Division, Foster City, CA, USA) following manufacturer's instructions, with a final volume of $10 \mu \mathrm{L}$. The dye-labeled sequencing products were run on an ABI PRISM 3100 Genetic Analyzer (Applied Biosystems). Results were edited using BioEdit (version 7.2.5, Hall 
1999), then assembled using Sequencher DNA sequence analysis software (version 4.7, Gene Codes, Ann Arbor, MI, USA). Sequences were confirmed as LV-specific using BLAST (Basic Alignment Search Tool; National Center for Biotechnology Information Bethesda, MD, USA, 2017). Unique sequences were identified using DNAcollapser (http://usersbirc.au.dk/biopv/php/fabox/dnacollapser), and sequence identities were determined using ClustalX (Larkin et al. 2007) with default settings. To study the relative genetic divergence among the LV sequences, the proportion of conserved sites among, and pairwise distances between, sequences were calculated at the nucleotide level with MEGA7 (Molecular Evolutionary Genetics Analysis version 7.0; Kumar et al. 2016), with the p-distance method as the model of nucleotide substitution, applying equal weighting to transitions and transversions, and complete deletion of gaps. All unique sequences are available on Genbank (Accession numbers [To be published online on acceptance of the manuscript for publication]).

A cartogram of LV-RNA presence and distribution for all small mammal species combined with sampling effort (Figure 1) was generated using ScapeToad (http://scapetoad.choros.ch/) and a standard treatment of diffusion given by: $J=v(r, t) \rho(r, t)$, where $v(r, t)$ and $\rho(r, t)$ correspond to the velocity and density at a given position $(r)$ and time (t) (Gastner and Newman 2004). ScapeToad uses two metrics implemented on a previously generated grid (cell size $=10 \mathrm{~km}^{2}$ ): the number of observations per cell (overall individual captures) and the number of LV-RNA PCR-positive individuals.

\section{Statistical analysis}

All statistical analyses were performed using the R package stats (R Development Core Team 2016).

Geographic distances were calculated between each pair of LV-RNA PCR-positive individuals, taking into account the earth's curvature, using the $\mathrm{R}$ package raster $(\mathrm{R}$ 
Development Core Team 2016). To test the correlation between genetic and geographical pairwise distances, simple Mantel tests (Mantel 1967) were used in the R package ape.

Land cover information was obtained from the European Corine Land Cover map (CLC, 2006, Version 17, http://www.eea.europa.eu/data-and-maps/data/corine-land-cover-2006raster-2/\#tab-documents). Based on a 3-level hierarchical classification system, the CLC provides information on the biophysical characteristics of the Earth's surface. Land cover categories (levels 1, 2 and 3, https://land.copernicus.eu/eagle/files/eagle-relatedprojects/pt clc-conversion-to-fao-lccs3 dec2010) were extracted from a single pixel (resolution of 250 meters) containing the coordinates of each trapping site. Elevation was obtained for each sampling site, using the European Digital Elevation Model (EU-DEM; http://www.eea.europa.eu/data-and-maps/data/eu-dem), with a spatial resolution of 25 meters.

Mean land surface temperature and precipitation (daily $\mathrm{mm}$ of precipitation, and number of days with precipitation) were estimated for the six months preceding each trapping date. Mean temperatures were obtained from the EuroLST database of gap-free daily MODIS LST maps (available at the Fondazione E. Mach; Metz et al. 2014), with a spatial resolution of 250 $\mathrm{m}$, while precipitation data were extracted from the ECA\&D dataset available at http://www.ecad.eu (Klein Tank et al. 2002).

To assess the association of individual (intrinsic) and environmental (extrinsic) factors with LV occurrence in bank voles in Europe, all available data on infection status of each bank vole from Finland, France, Germany, Italy and Sweden were analysed in a Generalized Linear Mixed Model (GLMM) with a binomial error distribution. The binary response variable was the presence or absence of LV-RNA, while explanatory variables were sex, 'age class', body mass, quadratic body mass, trapping season, country, trapping site (latitude/longitude/altitude of trapping location), land cover, mean daily temperature and mean daily precipitation of the six months preceding the trapping day. Preliminary analysis 
(Pearson's correlation and Variance Inflation Factor) indicated collinearity among some explanatory variables; therefore, the following were removed: country, longitude, temperature and 'age class' of individual voles. In addition, we considered only agricultural and forest land cover categories, as other categories were under-sampled. As voles in different countries were not sampled in the same years (see Table 1), year was treated as a random effect. Starting from the maximum model, which included all non-collinear explanatory variables, we carried out a multi-model selection approach (Burnham and Anderson, 2002) based on Akaike Information Criterion correction (AICc; Akaike 1974); the model with fewer parameters within the range $\Delta \mathrm{AICc}<2$ was selected as the best parsimonious model.

We also applied a Generalized Linear Model (GLM) to determine differences in the LV prevalence in bank vole samples collected in Italy and Sweden, from which we had animals trapped for three consecutive years (2010-2012). In this case, year was treated as a quantitative fixed effect. The explanatory variables and model selection procedure for this analysis were the same as those listed above. In this case following collinearity analysis the following variables were removed: longitude, altitude, temperature, land cover and 'age class' of individual voles. All quantitative explanatory variables in both models were standardized before including them in the models.

\section{Results}

A total of 1685 rodents and insectivores belonging to 21 species from 12 European countries were collected and screened using LV-specific RT-PCR (Table 1). In total, LV-RNA was detected in samples from nine out of 12 countries, and in 12/21 species tested, including one of two commensal species: the house mouse (but not the black rat Rattus rattus) (Table 1). The only invasive species, the grey squirrel Sciurus carolinensis), was also LV-RNA PCRnegative, as were the striped field mouse (Apodemus agrarius), long-tailed field mouse ( $A$. 
sylvaticus) and common vole (Microtus arvalis), although it should be noted that these latter three species all had small sample sizes, and/or were collected from very few countries (Table 1). In this study, LV-RNA was detected for the first time in two vole species, the red vole (Myodes rutilus) and the root vole (Alexandromys oeconomus), as well as in two insectivore species, the bicolored white-toothed shrew (Crocidura leucodon) and the Valais shrew (Sorex antinorii) (Table 1). Overall, for all countries and species, LV-RNA PCR-prevalence was 9.8\% (166/1685), while overall LV prevalence in bank voles was 15.2\% (135/885), ranging from a minimum of $3.7 \%$ (in Slovakia) to $25.9 \%$ (in Italy; Table 1). Figure 1 shows that the highest overall LV-RNA PCR-prevalence in small mammals is found in the boreal area in northern Sweden and in the alpine area in northern Italy, with ranges of 15-26\%. In other areas, LV prevalence was lower (0.1-5.0\%), with only three sites with a range of prevalence ranging from 5-10\%; in several areas LV was not detected at all. However, as Figure 1 indicates, the highest values of LV prevalence were detected in trapping areas with a more intense sampling effort.

Out of the 185 bp LV-specific sequences, 99 sites (53.5\%) were conserved, especially at the 5' and 3' ends of this UTR fragment. Our sequences represented 80 haplotypes, which displayed no geographical or host-specific patterns (data available on request). In some cases, the same LV haplotypes were found in different animal species; for example, individuals of the bank vole, house mouse and yellow-necked mouse from different trapping sites occasionally carried the same haplotype. On the other hand, certain haplotypes were also found present in several countries, for example Finland and Italy, or Sweden and Italy. Seventy-three out of the 80 haplotypes included at least one LV sequence obtained from bank voles (data not shown). Genetic distance (sequence variation) showed a small but significant increase with increasing geographical distance when the whole dataset was considered (Mantel test, $\mathrm{P}<0.01$, although this is based on a low $\mathrm{R}^{2}$ vale (0.093). 
Land cover analysis ( $\mathrm{R}$ code available on request) identified three CLC level 1 classes (agricultural areas, forests and semi-natural areas, artificial surface), nine CLC level 2 classes (arable land, artificial, forest, heterogeneous agricultural areas, industrial, pastures, permanent crops, shrub and/or herbaceous vegetation associations and urban fabric), and fifteen CLC level 3 classes (annual crops associated with permanent crops, broad-leaved forest, complex cultivated patterns, coniferous forest, discontinuous urban fabric, fruit trees and berry plantation, land principally occupied by agriculture with significant areas of natural vegetation, mixed forest, moors and heathland, natural grasslands, non-irrigated arable land, pastures, sport and leisure facilities, transitional woodland-shrub). Overall, LV prevalence was higher in small mammals trapped in forested areas, i.e. coniferous forests (48.8\%) and woodland-shrubs (18.7\%).

The best parsimonious model for assessing which factors influenced LV-RNA occurrence in bank voles trapped in five European countries between 2006 and 2012 included as explanatory variables: body mass (and its quadratic term), trapping season, altitude and mean precipitation in the six months preceding the trapping date (Table 2). The effect of the quadratic body mass was significant $(\mathrm{P}=0.02)$, meaning that $\mathrm{LV}$ prevalence was higher in animals with an intermediate body mass. Compared to the voles trapped in autumn, LV occurrence was significantly lower in spring $(\mathrm{P}=0.02)$ but not in summer $(\mathrm{P}=0.07)$. The occurrence of LV-RNA in bank voles was higher in trapping sites located at higher altitudes (Table 2). Interestingly, the amount of precipitation was negatively correlated with LV occurrence $(\mathrm{P}<0.05)$; i.e., high precipitation in the six months preceding the trapping date was significantly correlated with a decrease of LV occurrence in our study.

The best model for assessing the occurrence of LV in bank voles trapped in Italy and Sweden in the period 2010-2012, included body mass (again with a positive linear term and a negative quadratic term), the year, the season and country of capture, and the mean precipitation in the six months preceding the date of capture (Table 3). The GLM results 
showed once again a significant and negative association of individual body mass with LV occurrence $(\mathrm{P}<0.001)$. In particular the effect of the year is negative $(\mathrm{P}<0.001)$ indicating a downward trend in LV prevalence from 2010 to 2012; LV occurrence was significantly lower both in spring and in summer respect to autumn $(\mathrm{P}<0.001)$; LV-RNA PCR-prevalence in bank voles detected in Italy was higher than in Sweden $(\mathrm{P}<0.001)$. Finally, also in this model, the amount of precipitation recorded during the six months preceding the trapping date was negatively correlated with LV occurrence $(\mathrm{P}<0.05)$ (Table 3). 


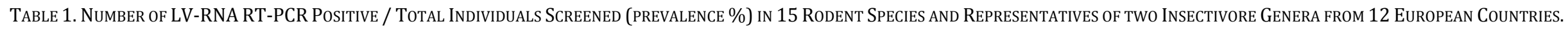

\begin{tabular}{|c|c|c|c|c|c|c|c|c|c|c|c|}
\hline Species & $\begin{array}{l}\text { Baltic } \\
\text { states }\end{array}$ & $H R$ & $D E$ & $F I$ & $F R$ & $I T$ & $N L$ & $S E$ & $S I$ & $S K$ & Total \\
\hline Trapping year(s) & 2012 & 2011-2012 & $2010-2013$ & $2010-2012$ & 2014 & 2006-2012 & $2007-2013$ & $2009-2012$ & 2012 & $2012-2013$ & \\
\hline Alexandromys oeconomus & - & - & - & $1 / 16(6.2)$ & - & - & - & - & - & - & $1 / 16(6.2)$ \\
\hline Apodemus agrarius & - & $0 / 18$ & - & - & - & - & - & - & $0 / 8$ & - & $0 / 26$ \\
\hline Apodemus flavicollis & - & $0 / 20$ & - & - & - & $5 / 101^{\mathrm{b}}(4.9)$ & - & - & $0 / 14$ & - & $5 / 135(3.7)$ \\
\hline Apodemus sylvaticus & - & $0 / 9$ & - & - & - & $0 / 2$ & - & - & $0 / 14$ & - & $0 / 25$ \\
\hline Craseomys rufocanus & - & - & - & $1 / 24(4.2)$ & - & - & - & - & - & - & $1 / 24(4.2)$ \\
\hline Lemmus lemmus & - & - & - & $5 / 218(2.3)$ & - & - & - & - & - & - & $5 / 218(2.3)$ \\
\hline Microtus agrestis & - & - & - & $4 / 29(13.3)$ & - & - & - & - & - & - & $4 / 29(13.3)$ \\
\hline Microtus arvalis & - & - & - & - & - & - & $0 / 9$ & - & - & - & $0 / 9$ \\
\hline Mus musculus & $1 / 23(4.4)$ & $1 / 22(4.5)$ & - & $0 / 3$ & - & $3 / 73(4.1)$ & - & - & $0 / 4$ & - & $5 / 125(4.0)$ \\
\hline Myodes glareolus & - & - & $13 / 100(13.0)$ & $5 / 21(23.8)$ & $11 / 100(11.0)$ & $33 / 127(25.9)^{\mathrm{b}}$ & $1 / 21(4.7)$ & $69 / 436(15.8)^{c}$ & - & $3 / 80(3.7)$ & $135 / 885(15.2)$ \\
\hline Myodes rutilus & - & - & - & $2 / 34(5.9)$ & - & - & - & - & - & - & $2 / 34(5.9)$ \\
\hline Myopus schisticolor & - & - & - & $3 / 26(11.5)$ & - & - & - & - & - & - & $3 / 26(11.5)$ \\
\hline Rattus rattus & - & $0 / 8$ & - & - & - & $0 / 12$ & - & - & - & - & $0 / 20$ \\
\hline Sciurus carolinensis ${ }^{d}$ & - & - & - & - & - & $0 / 29$ & - & - & - & - & $0 / 29$ \\
\hline Sciurus vulgaris & & & & & & $2 / 7(28.6)$ & & & - & & $2 / 7(28.6)$ \\
\hline Crocidura spp. ${ }^{e}$ & - & $0 / 1$ & - & - & - & $1 / 7(14.3)$ & - & - & - & - & $1 / 8(12.5)$ \\
\hline Sorex spp ${ }^{f}$ & - & - & $0 / 3$ & - & - & $2 / 66(3.0)$ & - & - & - & - & $2 / 69(2.9)$ \\
\hline Total & $1 / 23(4.3)$ & $1 / 78(1.3)$ & $13 / 103(12.6)$ & 21/371(5.7) & $11 / 100(11.0)$ & $46 / 424(10.8)$ & $1 / 30(3.3)$ & $69 / 436(15.8)$ & $0 / 40$ & $3 / 80(3.7)$ & $166 / 1685(9.8)$ \\
\hline
\end{tabular}

a: Baltic states: Estonia, Latvia, Lithuania; HR: Croatia; DE: Germany; FI: Finland; FR: France; IT: Italy; NL: The Netherlands; SE: Sweden; SI: Slovenia; SK: Slovakia.

b: 20 individuals analysed previously by Hauffe et al. (2010).

c: Myodes glareolus previously screened in Fevola et al. (2017a).

d: Previously screened in Romeo et al. (2010).

e: Crocidura leucodon, C. suaveolens (one sample of $C$. leucodon from Italy was LV-RNA PCR-positive).

f: Sorex alpinus, S. antinorii, S. coronatus, S. minutus (two samples of S. antinorii from Italy were LV-RNA PCR-positive) 


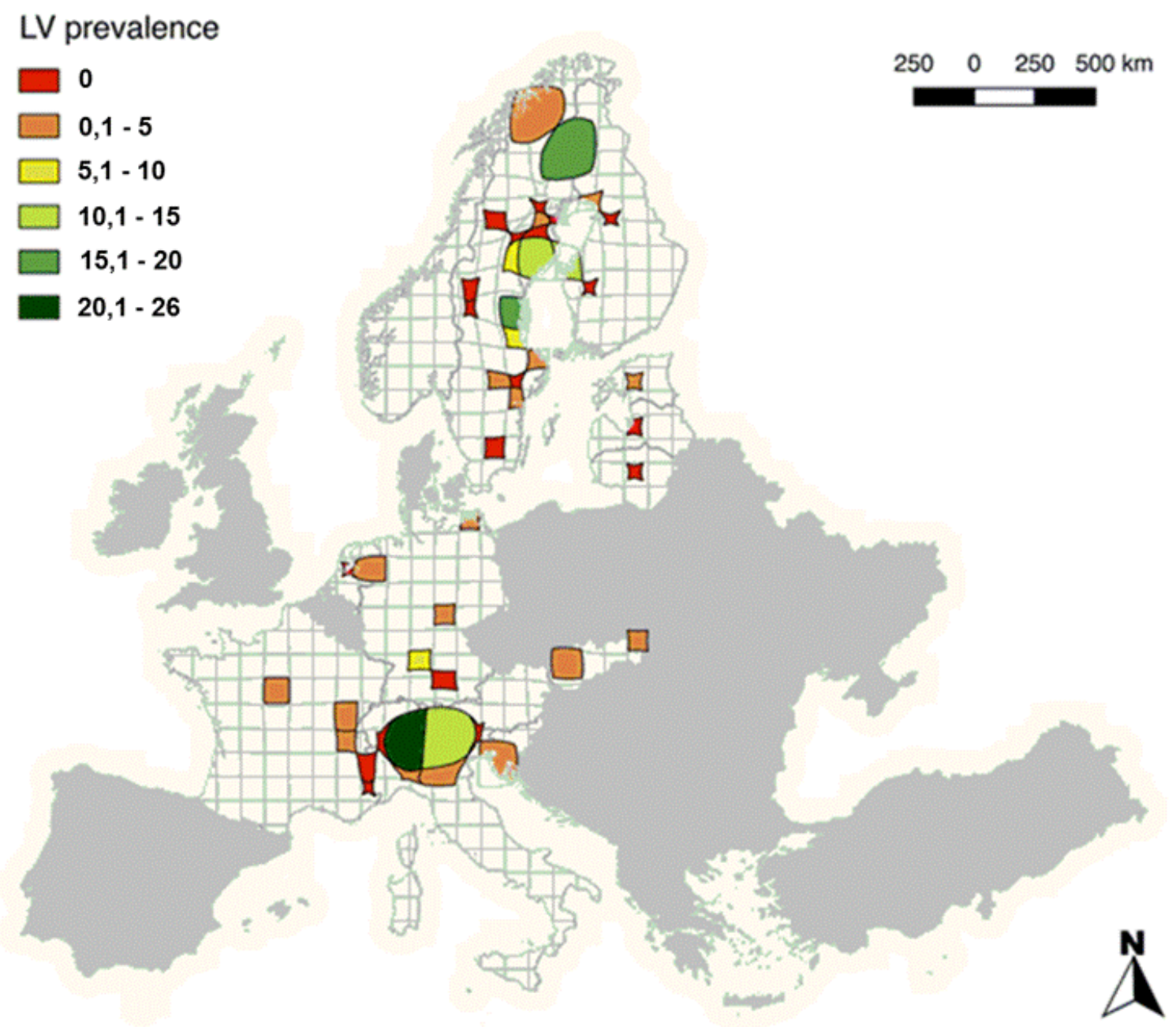

FIG. 1. Cartogram of Ljungan virus RNA prevalence (\%) in small mammals in Europe, showing how this varies with sampling effort. Sampling effort is given by the size of the cell, with the original size $\left(10 \mathrm{~km}^{2}\right)$ varying by the proportion of sampling occurring there. Sampling effort was calculated using the coordinates of each trapping site: the more samples from each cell, the greater was sampling effort for that cell. 
Table 2. Coefficient Estimates And Statistics Of Explanatory Variables Remaining In The Best

Parsimonious Selected Models For Predicting The OcCuRrence Of LJUngan Virus RNA In Bank Voles In Five EuRopean Countries From 2006-2012. All Estimates REFER To STANDARdizED VARIABles. REFEREnCE VALUe Was Autumn For 'SEASON'.

\begin{tabular}{lcccc}
\hline Variable & Estimate & Standard Error & z value $^{\mathrm{a}}$ & $\operatorname{Pr}(>|\mathrm{z}|)^{\mathrm{b}}$ \\
\hline Intercept) & -1.824 & 0.341 & -5.355 & $<0.001^{* * *}$ \\
Body mass & 2.355 & 1.243 & 1.895 & 0.058 \\
Quadratic body mass & -3.220 & 1.379 & -2.334 & $0.020^{*}$ \\
Season_Spring & -0.699 & 0.301 & -2.321 & $0.020^{*}$ \\
Season_Summer & -0.866 & 0.482 & -1.796 & 0.072 \\
Altitude & 0.588 & 0.203 & 2.903 & $0.004^{* *}$ \\
Pmean_six_months & & & & $0.010^{*}$ \\
\hline
\end{tabular}

a Estimate to Standard Error ratio.

b Two-tailed P values for $\mathrm{Z}$ statistics; significance level: ${ }^{* * *} \mathrm{P}<0.001 ;{ }^{* *} \mathrm{P}<0.01 ;{ }^{*} \mathrm{P}<0.05$.

c Mean precipitation for the previous six months 
Table 3. Coefficient Estimates And Statistics Of EXPlanatory Variables Remaining In The Best Selected Models For Predicting The OCCURRENCE LJUngan Virus RNA In Bank Voles In ITALY AND SWEDEN ONLY, From 2010-2012. All Estimates ReFER to STANDARdized VARIABLES. REFERENCE Values Were Italy For 'Country' And Autumn For 'SeAson'.

\begin{tabular}{lcccc}
\hline Variable & Estimate & Std. Error & $\mathrm{z} \mathrm{value}^{\mathrm{a}}$ & $\operatorname{Pr}(>|\mathrm{z}|)^{\mathrm{b}}$ \\
\hline (Intercept) & 0.911 & 0.619 & 1.473 & 0.141 \\
Body mass & 4.031 & 1.934 & 2.085 & $0.037^{*}$ \\
Quadratic body mass & -4.880 & 2.127 & -2.294 & $0.022^{*}$ \\
Year & -0.638 & 0.168 & -3.804 & $<0.001^{* * *}$ \\
Country_Sweden & -3.098 & 0.719 & -4.310 & $<0.001^{* * *}$ \\
Season_Spring & -2.437 & 0.543 & -4.486 & $<0.001^{* * *}$ \\
Season_Summer & -2.991 & 0.718 & -4.165 & $<0.001^{* * *}$ \\
Pmean_six_months & -1.2378 & 0.332 & -3.733 & $<0.001^{* * *}$ \\
\hline
\end{tabular}

a Estimate to Standard Error ratio.

b Two-tailed $\mathrm{P}$ values for $\mathrm{Z}$ statistics; significance level: ${ }^{* * *} \mathrm{P}<0.001$; ${ }^{* *} \mathrm{P}<0.01 ;{ }^{*} \mathrm{P}<0.05$.

${ }^{\mathrm{c}}$ Mean precipitation for the previous six months 


\section{Discussion}

The prevalence of LV-RNA in 21 species of rodent and insectivore was assessed to document the geographical and host distribution of LV in 12 European countries, and to better understand the association of LV prevalence in bank voles with various intrinsic and extrinsic factors.

Here we showed that LV is widespread, both geographically (nine out of 12 countries) and among potential rodent and insectivore host species (12 out of 21 species screened here), although not in all tested commensal species, such as rats (see also Cuong et al. 2015). This brings the total number of LV-positive countries to 12 (those listed in Table 1 plus Denmark, UK and USA), and potential small mammal host species to 14 (those listed in Table 1 plus the montane vole and southern red-backed vole), including eight vole species. The overall LV-RNA PCR-prevalence of $9.8 \%$ (all hosts and countries; standard error: 1.7\% per country, 1.9\% per species) is within the range of our previous screening of bank voles in Sweden and Finland only (16.2\%; Fevola et al. 2017a), and bank vole screenings in other countries by other authors (UK: 27.0\%; Salisbury et al. 2014; Finland: 18\%; Jääskeläinen et al. 2013; Germany: 8.4\%; Kallies 2010; Italy: 50.0\%; Hauffe et al. 2010). Prevalence in the yellow-necked mouse and the house mouse is lower compared to previous reports (yellow-necked mouse: 10\%, Hauffe et al. 2010; house mouse: 25\%, Kallies 2010; 26.1\%, Salisbury et al. 2014); but within the previously reported range for field vole (0.6\%, Forbes et al. 2014; 17\%, Kallies 2010).

In Finland and Italy, where samples from several species were available, we found LV-RNA PCR-positive individuals from almost all the species. In particular, in Lapland, Finland (2 sites) seven out of eight rodent species screened were LV-RNA PCR-positive, and in northern Italy (4 sites), six out of 12 were positive (Table 1). For both these examples, bank voles had the highest prevalence of all potential host species, implying they are the main host for $\mathrm{LV}$, as has been suggested previously (Tapia et al. 2010; Fevola et al. 2017a). Nonetheless, susceptibility 
of potential host species to LV should be tested by experimental infection before they can be considered true hosts. The presence of LV-RNA PCR-positive animals of other rodent and insectivore species with a lower or much lower prevalence may be a consequence of a spillover from bank voles to other susceptible species. This 'spillover' phenomenon has been described for Puumala orthohantavirus (PUUV) between bank voles and long-tailed field mice, for Dobrava-Belgrade virus (strain Dobrava) between striped field mice (A. agrarius) and yellow-necked mice, and for Tula orthohantavirus between common and field voles sharing the same habitat (Klingström et al. 2002; Schlegel et al. 2009; Schmidt et al. 2016). However, this is not always the case, since LV-RNA was clearly present in rodent communities in Kilpijärvi, Finland (northern-most polygon in Fig. 1; albeit at lower prevalences than that found in the bank vole), where bank voles do not occur.

The distribution of LV-RNA PCR-positive individuals was heterogeneous across study sites. If the transmission of LV is direct and density dependent, the spread and persistence of the virus would depend on the number and type of contacts between hosts (Swinton 1998; Heyman et al. 2012). Because the density of small mammal species is different in various habitats (Escutenaire et al. 2002), various biotic and abiotic factors could influence the spatial heterogeneity of pathogen transmission (Sauvage et al. 2003). In our study, the highest LV prevalence was detected in trapping areas with a more intense sampling effort, as expected, since a higher sampling effort translates into a larger number of samples collected in that area, with a consequent higher possibility to detect the virus.

Our results showed a correlation between body mass and LV prevalence, in that animals with an intermediate body mass were the most infected both overall, and in Italy and Sweden only. Since body mass is correlated with functional group, these results support those of Fevola et al. (2017a), which showed a correlation between the 'age class' of bank voles and LV prevalence, in that nonbreeding subadults with intermediate body mass were more infected 
than (lighter) juveniles and (heavier) breeding adults. The results of these two studies together suggest that dispersal might be an important factor contributing to transmission, since in bank voles it is primarily subadults (individuals trapped in autumn that did not attain maturity during their first year) that show density-dependent dispersal (e.g. Hansson 1987, Ecke et al. 2002). However, unlike PUUV infection, which is chronic and results in the oldest animals having the highest prevalence (Vapalahti et al. 2003; Kallio et al. 2007; Reusken and Heyman 2013; Voutilainen et al. 2016), the present study suggests that LV is not persistent, and bank voles might clear the infection later in life. Interestingly, in human LV serological studies, waning immunity with age has also been observed (Jääskeläinen et al. 2016).

Overall LV prevalence was higher in small mammals trapped at higher altitudes and in forested areas, particularly in woodland, broad-leaved forest and coniferous forests compared to arable land and heterogeneous agricultural areas. Since forest environments provide more favorable bank vole habitat (higher quality food resources; more stable climate) than fragmented, heterogeneous landscape (Guivier et al. 2011; Heyman et al. 2012), the higher prevalence in woodland may be due to bank vole density and behavior in this habitat type. Forest fragmentation also seems to decrease the prevalence of PUUV in Belgium for the same reasons (Linard et al. 2007; Vaheri et al. 2013; but see Magnusson et al. 2015 for Sweden). However, this result was heavily influenced by the high number of forest-dwelling bank voles screened in these habitats in Italy and Sweden compared to species living in arable land or other habitats. Favorable habitat might influence population dynamics in other ways that influence pathogen transmission; for example, higher turnover or population growth rates result in a higher proportion of younger nonbreeding subadult hosts, which the results of this study indicate are more likely to be infected with LV.

Our study showed that high precipitation in the six months prior the trapping date was significantly correlated with a decrease of LV prevalence in bank voles. This correlation could 
be due to the effect of climatic conditions on the survival of viruses in the environment outside their hosts (Hurst et al. 1980; Kallio et al. 2006), or the survival of infected host. The survival of LV in the environment is not known (but see Ekström et al. 2007 for laboratory studies), nor is the survival of LV-infected bank voles. However, our results are consistent with previous studies that observed the effect of weather conditions on host activity, which in turn affected their exposure to viral infection. For example, precipitation during the autumn prior to sampling was shown to negatively influence PUUV prevalence in bank voles (Linard et al. 2007). As rainfall tends to diminish the activity of bank voles and thus the contact between individuals (Wróbel and Bogdziewicz 2015), it follows that the potential to transmit the virus may also decrease with increased rainfall. In addition, environmental regulators such as climate and habitat quality affect both direct and indirect transmission, through their effect on rodent reproductive success, host population abundance and dispersal (Kozakiewicz 2000; Davis et al. 2005; Mills 2005; Linard et al. 2007). For PUUV, it is known that viral transmission between bank voles is driven by viral excretion into the environment and the survival of the virus outside the host (Kallio et al. 2006; Heyman et al. 2012; Voutilainen et al 2015), LV transmission and the factors affecting it still need to be elucidated.

Temporal variation was also noted in LV prevalence; that is, overall prevalence was significantly lower in spring compared to autumn. Because vole population density is usually the highest at the beginning of autumn just before the end of the breeding season (Bujalska 1996; Tadin et al. 2014) and includes a higher proportion of subadult animals, a higher prevalence at this time of year might be due to closer contact among nonterritorial and nonaggressive subadult infected and susceptible individuals, thus increasing the possibility of virus transmission between them. Moreover, since animals' immune status can be compromised during the breeding season, due to demanding physiological activities (Martin et al. 2008), this may increase the probability of breeding adults getting infected by increasing 
susceptibility. The lower prevalence of LV in bank voles in spring is coherent with the hypothesis of the clearing of the infection from bank voles as they mature, as already proposed by Fevola et al. (2017a) and discussed above, but also with high winter mortality of this species, which may be exacerbated by the virus (Niklasson et al. 2006). There was no association of $\mathrm{LV}$ prevalence with sex; however, if vole activity is at the core of $\mathrm{LV}$ transmission, we would expect males to be more infected, as their mobility in the reproductive season is markedly higher than that of females, and they frequently leave their home range and visit shelters of other animals (Bernshtein et al. 1999).

We found a high level of variation among LV sequences (46.5\% of variant sites), even though the 185 bp LV-specific fragment is from the UTR, a purportedly 'conserved' part of the genome (Johansson et al. 2002; Donoso-Mantke et al. 2007). The 5' UTR is the most highly conserved region in many other virus genomes, such as those of enteroviruses, the foot-andmouth disease virus (FMDV) in the Picornaviridae family, and the hepatitis C virus (HCV), a member of the Flaviviridae family. In Smith et al. (1995), 77\% of nucleotide positions in the 5' UTR were invariant among all the sequences of HCV surveyed, and between the enteroviruses and FMDV strains, the average sequence similarities were 80-95\% (Rivera et al. 1988; Santti et al. 1999; Carrillo et al. 2005). The high number of haplotypes found in this study indicates that LV maintains a high level of variation compared to other viruses, possibly as a result of a wide host range, necessitating adaptation to different host genomes and immunities. However, in contrast to PUUV and TULV (Tula orthohantavirus virus; see Saxenhofer et al. 2017), only weak isolation by distance was revealed for LV. This result could be explained by the relatively short length of the fragment analysed and needs to be confirmed. In contrast, whole genome studies of Pounder et al. (2015) suggested that LV was evolving slowly. However, that study used laboratory strains of the LV virus. Further phylogenetic analyses of LV are ongoing to better characterize the various LV strains and understand its evolutionary 
history, especially because, due to the high strain diversity in Parechoviruses, it is not clear if rodent and humans strains of LV are the same (Jääskeläinen et al. 2016).

Our results show that $\mathrm{LV}$ is widespread across Europe and its micromammal communities, and provide further support for the bank voles as the main viral host (Fevola et al. 2017a), particularly subadults. In addition, we noted a temporal pattern of prevalence (higher in autumn), and we show for the first time that higher prevalence is associated with lower precipitation, woodland habitats, and higher altitude; both these results are likely associated with subadult bank vole behavior affecting transmission. Although the zoonotic potential of LV is now considered unlikely (Fevola 2019) and high human seroprevalence has not yet been linked to transmission from rodents, these variables (lower precipitation, woodland habitats, and higher altitude, higher densities of subadults) may represent potential risk factors for human contact with the virus. Research on the zoonotic potential of LV and association of human LV seroprevalence with these environmental variables is ongoing.

\section{Acknowledgments}

This research was made possible by a FIRST PhD School scholarship from the Fondazione Edmund Mach to C.F. Laboratory work was funded by the EU grant FP7-261504 EDENext to A.R., H.H., R.G.U. and H.C.H and by Sigrid Jusélius Foundation. Sample collection in Sweden was financed by grants from the Swedish Environmental Protection Agency (via the National Environmental Monitoring Programme for small rodents and Alvins fond) to B.H.; the Stiftelsen Oscar och Lili Lamms minne to B.H. and F.E.; the VINNOVA (P32060-1) to F.E.; the Swedish Research Council Formas (221-2012-1562) to F.E., B.H., and G.E.O.; the National Environmental and Wildlife Monitoring and Assessment program (FoMA, http://www.slu.se/en/environment) to G.E.O. and the Helge Ax:son Johnsons Stiftelse to M.M. We also thank Edvinas Rommel for help with the European Corine Land Cover map. The 
manuscript is catalogued by the EDENext Steering Committee as EDENext385 (http://

www.edenext.eu/). The contents of this publication are the sole responsibility of the authors and do not necessarily reflect the views of the European Commission.

\section{Author Disclosure Statement}

No conflicting interests exist. 


\section{References}

Akaike H. A new look at the statistical model identification. IEEE transactions on automatic control. 1974;19:716-23.

Bernshtein AD, Apekina NS, Mikhailova TV, Myasnikov YA, et al. Dynamics of Puumala hantavirus infection in naturally infected bank voles (Clethrinomys glareolus). Arch Virol. 1999;144:2415-28.

Burnham, KP, Anderson DR. Model selection and inference: a practical information-theoretic approach. 2nd Edition. 2002.

Bujalska G. Population dynamics in Clethrionomys glareolus (Schreber, 1780). In: Proceedings of the 1st European Congress of Mammalogy. 1996;1:163-176.

Carrillo C, Tulman ER, Delhon G, Lu Z, et al. Comparative genomics of Foot-and-Mouth Disease Virus. J Virol. 2005;79:6487-6504.

Cuong NV, Carrique-Mas J, Vo Be H, et al. Rodents and risk in the Mekong delta of Vietnam: seroprevalence of selected zoonotic viruses. Vector Borne Zoonotic Dis. 2015;15:65-72.

Davis S, Calvet E, Leirs, H. Fluctuating rodent populations and risk to humans from rodentborne zoonoses. Vector Borne Zoonotic Dis. 2005;5:305-14.

Donoso Mantke O, Kallies R, Niklasson B, Nitsche A, et al. A new quantitative real-time reverse transcriptase PCR assay and melting curve analysis for detection and genotyping of Ljungan virus strains. J Virol Methods. 2007;141:71-77.

Ecke F, Löfgren O, Sörlin D. Population dynamics of small mammals in relation to forest age and structural habitat factors in northern Sweden. J Appl Ecol. 2002;39:781-792. 
Ekström JO, Tolf C, Edman KA, Lindberg M. Physicochemical properties of the Ljungan Virus prototype virion in different environments: inactivated by heat but resistant to acidic $\mathrm{pH}$, detergents and non-physiological environments such as Virkon®-containing solutions. Microbiol Immunol. 2007;51:841-850.

Escutenaire S, Chalon P, De Jaegere F, Karelle-Bui F, et al. Behavioral, physiologic, and habitat influences on the dynamics of Puumala virus infection. Emerg Infect Dis. 2002;8:930-936.

Fevola C, Forbes KM, Mäkelä S, Putkuri N, et al. Lymphocytic choriomeningitis, Ljungan and orthopoxvirus seroconversions in patients hospitalized due to acute Puumala hantavirus infection. J Clin Virol. 2016;84:48-52.

Fevola C, Rossi C, Rosa R, Nordstrom $\AA$, et al. Distribution and seasonal variation of Ljungan virus in bank voles (Myodes glareolus) in Fennoscandia. J Wildl Dis. 2017a;53:552-560.

Fevola C, Kuivanen S, Smura T, Vaheri A, et al. Seroprevalence of lymphocytic choriomeningitis virus and Ljungan virus in Finnish patients with suspected neurological infections. J Med Virol. 2017b;90:429-35.

Fevola C. Distribution and clinical associations of Ljungan virus (Parechovirus B). University of Helsinki. 2019.

Forbes KM, Voutilainen L, Jääskeläinen A, Sironen T, et al. Serological survey of rodent-borne viruses in Finnish field voles. Vector Borne Zoonotic Dis. 2014;14:278-283.

Gastner MT, Newman MEJ. From The Cover: Diffusion-based method for producing densityequalizing maps. Proc Natl Acad Sci. 2004;101:7499-7504.

Guivier E, Galan M, Chaval Y, Cosson JF, et al. Landscape genetics highlights the role of bank vole metapopulation dynamics in the epidemiology of Puumala hantavirus. Mol Ecol. 2011;20:3569-3583. 
Hall TA. BioEdit: a user-friendly biological sequence alignment editor and analysis program for Windows 95/98/NT. Nucleic Acids Symp Ser. 1999;41:95-98.

Hansson L. Dispersal routes of small mammals at an abandoned field in central Sweden. Holarctic Ecol. 1987;10:154-159.

Hauffe HC, Niklasson B, Olsson T, Bianchi A, et al. Ljungan virus detected in bank voles (Myodes glareolus) and yellow-necked mice (Apodemus flavicollis) from Northern Italy. J Wildl Dis. 2010;46:262-266.

Heyman P, Thoma BR, Marié J Lou, Cochez C, et al. In search for factors that drive hantavirus epidemics. Front Physiol. 2012;3:1-23.

Hurst CJ, Gerba CP, Cech I. Effects of environmental variables and soil characteristics on virus survival in soil. Appl Environ Microbiol. 1980;40:1067-1079.

Jääskeläinen AJ, Kolehmainen P, Voutilainen L, Hauffe HC, et al. Evidence of Ljungan virus specific antibodies in humans and rodents, Finland. J Med Virol. 2013;85:2001-2008.

Jääskeläinen AJ, Voutilainen L, Lehmusto R, Henttonen H, et al. Serological survey in the Finnish human population implies human-to-human transmission of Ljungan virus or antigenically related viruses. Epidemiol Infect. 2016;144:1278-1285.

Jackson CM. On the recognition of sex through external characters in the young rat. Biol Bull. 1912;23:171-173.

Johansson ES, Niklasson B, Maizel J, Gorbalenya AE, et al. Molecular analysis of three Ljungan virus isolates reveals a new, close-to-root lineage of the Picornaviridae with a cluster of two unrelated 2A proteins. J Virol. 2002;76:8920-8930. 
Johansson ES, Niklasson B, Tesh RB, Shafren DR, et al. Molecular characterization of M1146, an American isolate of Ljungan virus (LV) reveals the presence of a new LV genotype. J Gen Virol. 2003;84:837-844.

Kallies R. Ljungan virus-prevalence in rodents and virus pathogenesis. Freie Universität Berlin, 2010.

Kallio ER, Klingström J, Gustafsson E, Manni T,et al. Prolonged survival of Puumala hantavirus outside the host: evidence for indirect transmission via the environment. J Gen Virol. 2006;87:2127-2134.

Kallio ER, Voutilainen L, Vapalahti O, Vaheri A, et al. Endemic hantavirus infection impairs the winter survival of its rodent host. Ecology. 2007;88:1911-1916.

Klein Tank AMG, Wijngaard JB, Können GP, Böhm R, et al. Daily dataset of 20th-century surface air temperature and precipitation series for the European Climate Assessment. Int J Climatol. 2002;22:1441-1453.

Klingström J, Heyman P, Escutenaire S, Sjölander KB, et al. Rodent host specificity of European hantaviruses: evidence of Puumala virus interspecific spillover. J Med Virol. 2002;68:581588.

Kozakiewicz M. Landscape approach to bank vole ecology. Polish J Ecol. 2000;48:149-161.

Kumar S, Stecher G, Tamura K. MEGA7: Molecular Evolutionary Genetics Analysis version 7.0 for bigger datasets. Mol Biol Evol. 2016;33:1870-1874.

Larkin MA, Blackshields G, Brown NP, Chenna R, et al. Clustal W and Clustal X version 2.0. Bioinformatics. 2007;23:2947-2948. 
Linard C, Tersago K, Leirs H, Lambin EF. Environmental conditions and Puumala virus transmission in Belgium. Int J Health Geogr. 2007;6:55-66.

Magnusson M, Ecke F, Khalil H, Olsson G, et al. Spatial and temporal variation of hantavirus bank vole infection in managed forest landscapes. Ecosphere. 2015;6:1-8.

Mantel, N. The detection of disease clustering and a generalized regression approach. Cancer research. 1967;27:209-220.

Martin LB, Weil ZM, Nelson RJ. Seasonal changes in vertebrate immune activity: mediation by physiological trade-offs. Philos Trans Royal Soc B. 2008;363:321-39.

Metz M, Rocchini D, Neteler M. Changes with remote sensing at unprecedented detail. Remote Sens. 2014;6:3822-3840.

Mills JN. Regulation of rodent-borne viruses in the natural host: implications for human disease. Arch Virol Suppl. 2005;19:45-57.

Niklasson B, Hörnfeldt B, Lundman B. Could myocarditis, insulin-dependent diabetes mellitus, and Guillain-Barré syndrome be caused by one or more infectious agents carried by rodents? Emerg Infect Dis. 1998;4:187-193.

Niklasson B, Kinnunen L, Hörnfeldt B, Hörling, J, et al. A new Picornavirus isolated from bank voles (Clethrionomys glareolus). Virology. 1999;255:86-93.

Niklasson B, Heller KE, Schønecker B, Bildsøe M, et al. Development of type 1 diabetes in wild bank voles associated with islet autoantibodies and the novel Ljungan virus. Int J Exp Diabesity Res. 2003;4:35-44.

Niklasson B, Nyholm E, Feinstein RE, Samsioe A, et al. Diabetes and myocarditis in voles and lemmings at cyclic peak densities-induced by Ljungan virus? Oecologia. 2006;150:1-7. 
Niklasson B, Samsioe A, Papadogiannakis N, Kawecki A, et al. Association of zoonotic Ljungan virus with intrauterine fetal deaths. Birth Defects Res Part A Clin Mol Teratol. 2007;79:488493.

Niklasson B, Almqvist PR, Hörnfeldt B, Klitz W. Sudden infant death syndrome and Ljungan virus. Forensic Sci Med Pathol. 2009a;5:274-290.

Niklasson B, Samsioe A, Papadogiannakis N, Gustafsson S, et al. Zoonotic Ljungan virus associated with central nervous system malformations in terminated pregnancy. Birth Defects Res Part A - Clin Mol Teratol. 2009b;85:542-545.

Pounder KC, Watts PC, Niklasson B, Kallio ER, et al. Genome characterisation of two Ljungan virus isolates from wild bank voles (Myodes glareolus) in Sweden. Infect Genet Evol. 2015;36:156-164.

Prévot-Julliard AC, Henttonen H, Yoccoz NG. and Stenseth N.C. Delayed maturation in female bank voles: optimal decision or social constraint?. J Anim Ecol. 1999; 68:684-697.

R Development Core Team. R: A Language and Environment for Statistical Computing. R Foundation for Statistical Computing, Vienna. 2016.

Reusken C, Heyman P. Factors driving hantavirus emergence in Europe. Curr Opin Virol. 2013;3:92-99.

Rivera VM, Welsh JD, Maizel J V. Comparative sequence analysis of the 5' noncoding region of the enteroviruses and rhinoviruses. Virology. 1988;165:42-50.

Romeo C, Ferrari N, Rossi C, Everest DJ, et al. Ljungan virus and an adenovirus in Italian squirrel populations. J Wildl Dis. 2014;50:409-411. 
Salisbury AM, Begon M, Dove W, Niklasson B, et al. Ljungan virus is endemic in rodents in the UK. Arch Virol. 2014;159:547-551.

Samsioe A, Papadogiannakis N, Hultman T, Sjöholm Å, et al. Ljungan virus present in intrauterine fetal death diagnosed by both immunohistochemistry and PCR. Birth Defects Res Part A - Clin Mol Teratol. 2009;85:227-229.

Santti J, Hyypiä T, Kinnunen L, Salminen M. Evidence of recombination among enteroviruses. J Virol. 1999;73:8741-8749.

Sauvage F, Langlais M, Yoccoz NG, Pontier D. Modelling hantavirus in fluctuating populations of bank voles: the role of indirect transmission on virus persistence. J Anim Ecol. 2003;72:1-13.

Saxenhofer M, Weber DM, Ulrich RG, Heckel G. Revised time scales of RNA virus evolution based on spatial information. Proc. R. Soc. B. 2017; 284.

Schlegel M, Klempa B, Auste B, Bemmann M, et al. Dobrava-Belgrade virus spillover infections, Germany. Emerg Infect Dis. 2009;15:2017-2020.

Schmidt S, Saxenhofer M, Drewes S, Schlegel M, et al. High genetic structuring of Tula hantavirus. Arch Virol. 2016;161:1135-49.

Smith DB, Mellor J, Jarvis LM, Davidson F, et al. Variation of the hepatitis C virus 5' non-coding region: implications for secondary structure, virus detection and typing. J Gen Virol. $1995 ; 76: 1749-1761$.

Swinton J. Extinction times and phase transitions for spatially structured closed epidemics. Bull Math Biol. 1998;60:215-230. 
Tadin A, Bjedov L, Margaletic J, Zibrat B, et al. High infection rate of bank voles (Myodes glareolus) with Puumala virus is associated with a winter outbreak of haemorrhagic fever with renal syndrome in Croatia. Epidemiol Infect. 2014;142:1945-1951.

Tapia G, Cinek O, Rasmussen T, Grinde B, et al. No Ljungan virus RNA in stool samples from the Norwegian environmental triggers of type 1 diabetes (MIDIA) cohort study. Diabetes Care. 2010;33:1069-1071.

Tersago K, Verhagen R, Leirs H. Temporal variation in individual factors associated with hantavirus infection in bank voles during an epizootic: implications for Puumala virus transmission dynamics. Vector Borne Zoonotic Dis. 2011;11:715-721.

Tolf C, Gullberg M, Johansson ES, Tesh RB, et al. Molecular characterization of a novel Ljungan virus (Parechovirus; Picornaviridae) reveals a fourth genotype and indicates ancestral recombination. J Gen Virol. 2009;90:843-853.

Vaheri A, Henttonen H, Voutilainen L. Hantavirus infections in Europe and their impact on public health. Rev Med Virol. 2013;23:35-49.

Vapalahti O, Mustonen J, Lundkvist Å, Henttonen H, et al. Hantavirus infections in Europe. Lancet Infect Dis. 2003;3:653-661.

Voutilainen L, Sironen T, Tonteri E, Tuiskunen A, et al. Life-long shedding and chronic viremia of Puumala Hantavirus in wild bank voles (Myodes glareolus). J Gen Virol. 2015;96:12381247.

Voutilainen L, Kallio ER, Niemimaa J, Vapalahti O, Henttonen H. Temporal dynamics of Puumala hantavirus infection in cyclic populations of bank voles. Sci Rep. 2016;6:21323. 
Warvsten A, Bjornfors M, Arvidsson M, Vaziri-Sani F, et al. Islet autoantibodies present in association with Ljungan virus infection in bank voles (Myodes glareolus) in northern Sweden. J Med Virol. 2017;89:24-31.

Wróbel A, Bogdziewicz M. It is raining mice and voles: which weather conditions influence the activity of Apodemus flavicollis and Myodes glareolus? Eur J Wildl Res. 2015;61:475-478. 


\section{Figure legend}

Figure 1. Cartogram of Ljungan virus RNA prevalence (\%) in small mammals in Europe, showing how this varies with sampling effort. Sampling effort is given by the size of the cell, with the original size $\left(10 \mathrm{~km}^{2}\right)$ varying by the proportion of sampling occurring there. Sampling effort was calculated using the coordinates of each trapping site: the more samples from each cell, the greater was sampling effort for that cell. 